EGU2020-13899

EGU General Assembly 2020

(c) Author(s) 2020. This work is distributed under

the Creative Commons Attribution 4.0 License.

\title{
Health Monitoring of Masonry Arch Bridges by Integration of GPR and InSAR Techniques
}

\author{
Valerio Gagliardi ${ }^{1}$, Luca Bianchini Ciampoli ${ }^{1}$, Fabio Tosti ${ }^{2}$, Andrea Benedetto ${ }^{1}$, and Amir M. Alani ${ }^{2}$ \\ ${ }^{1}$ Roma Tre University, Department of Engineering, Rome, Italy (valerio.gagliardi@uniroma3.it) \\ ${ }^{2}$ University of West London (UWL), School of Computing and Engineering, London, United Kingdom
}

Approximately 70,000 masonry arch bridge spans (brick and stone) are reported to exist in the United Kingdom with in excess of tens of thousands throughout Europe. A good portion of these bridges is still operational and form part of the road and rail network systems in many countries. However, a great majority of these structures require desperate repair and maintenance [1].

Non-destructive testing (NDT) methods such as ground penetrating radar (GPR), 3D laser scanning, accelerometer sensors and thermal cameras amongst many others have been used to assess and monitor such structures in the past few years [2]. However, research has proven that stand-alone or integrated use of ground-based techniques may not represent a definitive solution to some major structural issues, such as scour and differential settlements [3], as these require continuous monitoring and data collection on long-term basis. To that extent, use of satellite data-based synthetic aperture radar (SAR) interferometry (InSAR) has proven to be effective in measuring displacements of infrastructure [4] [5] and natural terrain [6] over longer periods of observation.

Within this context, the paper presents a new integrated monitoring approach including use of the GPR and the InSAR techniques to an historic masonry arch bridge - the Old Aylesford Bridge in Kent, UK - a $13^{\text {th }}$ century bridge, crossing the river Medway. Main objectives of the research were: (1) to prove the viability of low-frequency and high-frequency GPR systems in providing structural detailing of the bridge deck at different depths and resolutions; (2) to be able to measure structural displacements with a millimetre accuracy caused by the seasonal variation of the water level in the river and the river bed soil expansions. Results have proven the viability of the above process to form the basis for an integrated health monitoring mechanism.

\section{References}

[1] Alani, A.M., Tosti, F., Banks, K., Bianchini Ciampoli, L., Benedetto, A. Non-Destructive Assessment of a Historic Masonry Arch Bridge Using Ground Penetrating Radar and 3D Laser Scanner, IMEKO International Conference on Metrology for Archaeology and Cultural Heritage Lecce, Italy, October 23-25, 2017.

[2] Solla, M., Lorenzo, H., Rial, F.I., Novo, A. (2011). GPR evaluation of the Roman masonry arch bridge of Lugo (Spain), NDT\&Int., 44, 8-12. 
[3] Selvakumaran, S., Plank, S., Geiß, C., Rossi, C., Middleton, C. (2018). Remote monitoring to predict bridge scour failure using Interferometric Synthetic Aperture Radar (InSAR) stacking techniques, Int. J. .Appl. Earth Obs. and Geoinf. 73, 463-470.

[4] Tosti, F., Gagliardi, V., D'Amico, F. and Alani, A.M., Transport infrastructure monitoring by data fusion of GPR and SAR imagery information. TIS 2019 International Conference of Rome, 23-24 September 2019.

[5] Bianchini Ciampoli, L., Gagliardi, V., Clementini, C. et al. (2019). Transport Infrastructure Monitoring by InSAR and GPR Data Fusion. Surv Geophys. https://doi.org/10.1007/s10712-019-09563-7 